\title{
Tmj Therapy and Tourette's Syndrome Symptoms- A Review Article
}

\author{
Agata Kordyka ${ }^{1}$, Karolina Piwowarczyk ${ }^{1}$, N Med Karolina Walczyńska Dragon ${ }^{1 *}$, N Med Aleksandra \\ Nitecka Buchta ${ }^{1}$, Lek Med Gniewko Więckiewicz ${ }^{2}$ and Hab B Med Stefan Baron ${ }^{1}$ \\ ${ }^{1}$ Department of Temporomandibular Joint Dysfunction, Medical University od Silesia in Katowice, Poland \\ ${ }^{2}$ Department and Clinic of Psychiatry in Tarnowskie Gory, Medical University of Silesia, Poland
}

*Corresponding author: N Med Karolina Walczyńska Dragon, Department of Temporomandibular Joint Dysfunction, Medical

University od Silesia in Katowice, Poland

\section{ARTICLE INFO}

Received: 隠 January 13, 2020

Published: 蔧 January 22, 2020

Citation: Agata Kordyka, Karolina Piwowarczyk, N Med Karolina Walczyńska Dragon, N Med Aleksandra Nitecka Buchta, Lek Med Gniewko Więckiewicz, Hab B Med Stefan Baron. Tmj Therapy and Tourette's Syndrome Symptoms- A Review Article. Biomed J Sci \& Tech Res 24(5)-2020. BJSTR. MS.ID.004111.

\section{ABSTRACT}

Gilles de la Tourette's syndrome is characterised by a set of neuropsychiatric symptoms with not fully understood aetiology. Several environmental factors are responsible for the clinical presentation of the disease, which adds to the complicated process of inheriting these disorders. The diagnosis of Tourette's syndrome is based on clinical symptoms and family history. Among the characteristic symptoms, the occurrence of tics, both motor and vocal, as well as concomitant behavioural disorders are distinguished. Previous treatment of such patients focuses mainly on pharmacological alleviation of annoying symptoms, i.e. involuntary, repetitive movements or sounds and emotional disorders. Recently, however, a new hypothesis appeared regarding the treatment of Tourette's syndrome, which assumes that this disease is caused by excessive afferent impulse within the trigeminal nerve nuclei. The new non-invasive method of proposed treatment uses a special splint (neurocranial vertical distractor) applied to the teeth to relieve the pressure from the compressed structures, including the nerves, around the temporo-mandibular joint. Increasing interest in this method fills the optimism of both neurologists and patients.

Keywords: Tourette's Syndrome; Neurocranial Vertical Distractor; Occlusal Splint; Neurobehavioral Disorders

\section{Introduction}

A. The Gilles de la Tourette syndrome is a well-known disorder with numerous motor and vocal tics. Tics are repetitive movements or sudden and involuntary sounds [1]. They can also take a form of grunting, grimaces, blinking, sniffing or shrugging. Patients suffering from this disorder perform compulsive actions that may seem controversial to the environment, which includes saying vulgar words or making obscene gestures [2].

B. These compulsory activities are so-called motor, vocal and sensory tics. Motor and vocal tics can be divided into "simple" and "complex". One of the characteristic behaviours is to imitate movements of other people from the environment (echopraxia) or words spoken by them (echolalia). The patient may also tend to repeat his own words (palilalia) or to say indecent words (koprolalia) [3].

C. The Gilles de la Tourette Syndrome (GTS) is a disease of complex aetiology. Both genetic as well as environmental and autoimmune factors $[4,1]$ need to be considered. Metabolic disorders of neurotransmitters play an important role in the pathogenesis of Tourette syndrome. It was found that the abnormal balance between the inhibitory and excitatory systems, in the brain, may be manifested in the form of varying concentrations of glutamic acid and GABA in the serum, hence the conclusion that these compounds may be markers of the above syndrome [5]. 
D. Several criteria have been adopted for the diagnosis of Tourette's syndrome, which help with the diagnosis of this disease. The following are listed here: multiple motor tics and one or more vocal tics, with the incidence of tics either decreasing or increasing, but under the condition they are present for more than a year from the initial symptoms and the onset of the disease is before the age of 18, with a lack of other direct causes (such as: drugs, encephalitis, degenerative brain diseases) [6]. To recognize the described neurobehavioral disorder, the physician is obliged to exclude the occurrence of tics that are caused by external factors. Patients suffering from Tourette's syndrome may also exhibit obsessive-compulsive disorder, attention deficit or anxiety disorder and improper control of impulsive actions [6]. TS (Tourette syndrome) affects men more commonly. It is estimated that the incidence of this disease reaches $0.03-1.6 \%$ [3].

\section{Treatment}

A. The treatment of Tourette's syndrome is very difficult, complex and based on a multidisciplinary approach aimed at achieving tolerated level of suppression of tics. Great importance is attributed to behavioural therapy and educating the patient and his environment. Pharmacotherapy uses drugs that reduce the amount of catecholamines as well as alphaagonists, dopamine antagonists, benzodiazepines, SSRIs or stimulants. In patients with severe TS, neurosurgical treatment is undertaken using brain stimulation by means of electrodes. In simple and dystonic tics, a botulinum toxin can be used [6].

B. In foreign literature you can find interesting publications on the unique treatment of Tourette syndrome symptoms, that uses intra-oral apparatus called a neurocranial vertical distractor. Its actions eliminate unwanted neurobehavioral disorders via normally existing trigeminoreticular fibres and tracts [7].

Researchers in this area are convinced that the basis of movement disorders lies in the abnormalities within a combination of several CNS structures: thalamus, cortex and substantia nigra. They also believe that Tourette's syndrome is a motor disorder that occurs at the level of the spinal cord. They base their hypothesis on the observations showing that in persons suffering from TS habitual movements coexist with tics originating from the muscles innervated by the trigeminal nerve $[8,9]$. Extrapolating their observations, the authors conclude that tics may be caused by excessive stimulation of trigeminal signals through the trigeminal nerve due to dysfunctions in the temporo-mandibular joint.

In the case of masticatory system dysfunction, i.e. disorders involving the so-called upper quarter - the head, neck and shoulder girdle, chewing muscles start working excessively and spatial changes appear within the temporo-mandibular joints. In patients suffering from masticatory dysfunction, we observe a number of very nagging symptoms, including somatic symptoms, which are: persistent headaches reminiscent of migraines, symptoms similar to neuralgia of $n$. $V$, pain around the eyeballs, facial pain, tension in the face, head and neck, aches in the ears and tinnitus as well as nervous tics associated with hyper function of masticatory muscles. The abnormal position of the jaws in the acetabulum and the hyper function of the masticatory muscles trigger constant and painless pulses [10]. Due to the fact that stimulation of $\mathrm{n}$. $\mathrm{V}$ significantly increases both in patients suffering from masticatory dysfunctions as well as patients with Tourette's Syndrome, the treatment consisting of relaxation in the upper quad muscles and stabilization of the temporo-mandibular joint syndrome may reduce or eliminate Tourette's Syndrome symptoms.

C. In 2010, American scientists published the results of studies in which five patients, with the diagnosed Tourette syndrome, participated. Each of the participants looked for an alternative treatment in order to put a stop to tedious tics. To make the results of observations more credible, scientists decided to exclude participants from pharmacological treatment. A detailed dental examination, including assessment of the temporo-mandibular joint, showed that each patient had a deep bite. As a result, the vertical dimension of the joint gap was reduced. The treatment was based on the gradual reduction of vertical bite with the use of individual thickness pads (spacers). After correcting the bite to the height at which the tics disappeared, anatomical impressions were taken to make an occlusal splint. This creates an artificial occlusal surface, that determines the appropriate position of the head of the mandible in the joint space. After returning and adjusting the splints, further check-ups took place after 1, 3 and 6 months. The treatment resulted in regression of tics and prevention of relapse as well as a reduction in the intensity of obsessivecompulsive symptoms [7].

Thanks to the conducted research, we know that in the course of Tourette's syndrome, there are reflexes triggered by stimulation of the cranial nerve's $V$ sensory fibres, which then stimulates other cranial nerves (VII, IX, X) and neighbouring neurons. Serotonin is synthesised in the nuclei of these nerves, which as a result of excessive impulses is exhausted and due to short intervals between stimuli cannot be replenished in sufficient quantity. As a result of lower levels of this substance, obsessive-compulsive symptoms intensify. When constant stimulation of the $\mathrm{V}$ cranial nerve is interrupted, serotonin levels normalize, and as a result, neurobehavioral disorders are reduced or eliminated $[7,11]$.

\section{Summary}

A. Gilles de la Tourette's syndrome is a neurobehavioral disorder that makes it difficult for patients to properly perform many daily activities. People with this disorder are perceived negatively by the environment, which results in poor social life and exclusion from many social groups. Patients expect understanding and desire acceptance of their 
unusual and sometimes irritating behaviours. In treating TS a lot of importance is attributed to behavioural therapy and pharmacological treatment. However, it should be remembered that each patient is different and requires an individual approach, so these therapies should always be attempted even if there are more complex methods of treatment available.

B. The innovations in the proposed treatment of symptoms of Tourette syndrome, described in this article, suggests close cooperation between doctors in the field of neurology and dentistry is beneficial. Interdisciplinary therapy allows to create a suitably selected splint, which is designed to bring relief in the nagging symptoms of TS. Patients suffering from this disorder are struggling with the constraints of their own body every day, which is why every treatment that brings with it a shadow of hope to improve the quality of life deserves attention. In the light of modern medicine, everyone should have the right to use innovative therapeutic systems despite their still uncertain prognosis. Ethical approval was not necessary for preparation of this article. This publication was prepared without any external sources of funding.

\section{References}

1. Stępień A (2014) Neurologia. Medical Tribune Polska Warszawa 1.

2. Kenneth W Lindsay, Ian Bone, Geraint Fuller (2013) Seria podręczników ilustrowanych Neurologia I neurochirurgia. $5^{\text {th }}$ Edition.

\section{ISSN: 2574-1241}

DOI: $10.26717 /$ BJSTR.2020.24.004111

N Med Karolina Walczyńska Dragon. Biomed J Sci \& Tech Res

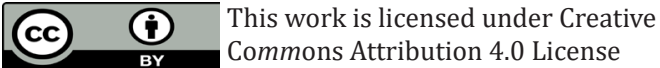

Submission Link: https://biomedres.us/submit-manuscript.php
3. Stephen L Hauser, Scott Andrew Josephson (2012) Harrison Naurologia w medycynie klinicznej. Neurology in clinical medicine p. 1-2.

4. Kowalska A, Midro AT, Janik P, Gogol A, Służewski W, et al. (2012) W poszukiwaniu genu zespołu Tourette’a. Część 2. Zmienność genomu chorych. Postępy Hig Med Dosw (online) 66: 89-95.

5. Janik P, Kalbarczyk A, Gutowicz M, Barańczyk Kuźma A, Kwieciński H (2010) Analiza stężenia wybranych neuroprzekaźników w surowicy chorych z zespołem Tourette'a. Neurologia i Neurochirurgia Polska 44(3): 251-259.

6. Elan D Louis, Stephan A Mayer, Lewis P Rowland (2017) Merritt Neurologia. (13 ${ }^{\text {th }}$ edn.) Polish edition by Edra Urban and Partner Wrocław 1-2.

7. Antony B Sims, Brendan C Stack (2010) An intraoral neurocranial vertical distractor appliance provides unique treatment for Tourette's syndrome and resolves comorbid neurobehavioral problems of obsessive-compulsive disorder. Medical Hypotheses 75(2): 179-184.

8. Versace V, Campostrini S, Sebastianelli L, Soda M, Saltuari L, et al. (2019) Adult-Onset Gilles de la Tourette Syndrome: Psychogenic or Organic? The Challenge of Abnormal Neurophysiological Findings. Front Neurol 10: 461 .

9. Pringsheim T, Holler Managan Y, Okun MS, Jankovic J, Piacentini J, et al. (2019) Comprehensive systematic review summary: Treatment of tics in people with Tourette syndrome and chronic tic disorders. Neurology 92(19): 907-915.

10. Grant Ritchey (2016) Use of Dental Appliances in the Management of Tourette Syndrome. Science Based Medicine.

11. Tilling F, Cavanna AE (2019) Relaxation therapy as a treatment for tics in patients with Tourette syndrome: a systematic literature review. Neurol Sci.

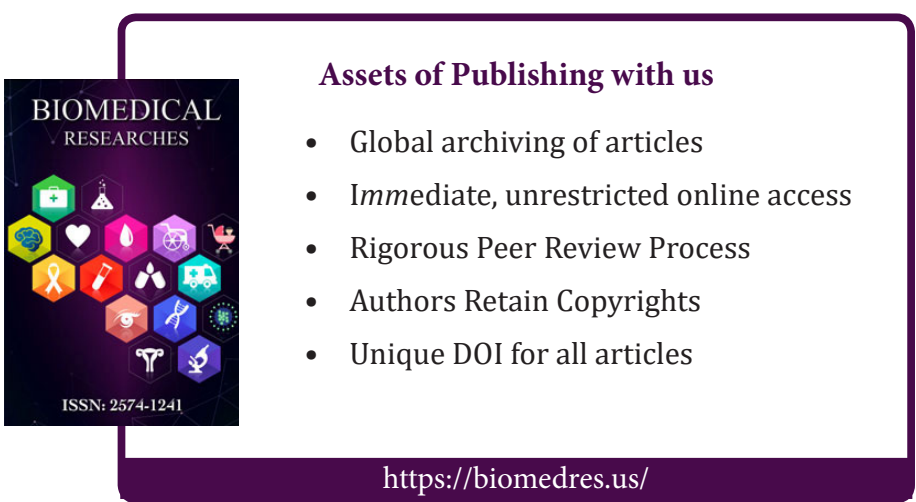

